\title{
Purification and Characterization of p68/70, Regeneration- Associated Proteins from Goldfish Brain
}

\author{
Michael L. Leski and Bernard W. Agranoff \\ Department of Biological Chemistry and Mental Health Research Institute, University of Michigan, \\ Ann Arbor, Michigan, U.S.A.
}

\begin{abstract}
Two acidic proteins (p68/70) previously shown to be associated with regeneration of the goldfish optic nerve were purified 887-fold from brain homogenates of Carassius auratus. Purification to homogeneity was achieved by sequential chromatography of a $100,000 \mathrm{~g}$ brain supernatant fraction on DEAE-Sephacel, $\mathrm{Cu}^{2+}$. charged iminodiacetic acid agarose, and gel filtration. The Stokes radius of the doublet was determined to be $5.8 \mathrm{~nm}$, and the sedimentation coefficient calculated to be 5.2 . From these values a molecular mass of $128 \mathrm{kDa}$ and a frictional coefficient ratio of 1.6 were calculated. Chromatofocusing on a high-resolution DEAE column resolved the protein doublet into three dimeric species of p68, p68/70, and $p 70$. These results indicate that the proteins are highly elongated and associate as homodimers or as a heterodimer. Subcellular localization and membrane extraction experiments indicated p68/70 to be a component of the plasma membrane associated primarily through hydrophobic interactions. p68/70 demonstrated biphasic behavior in phase partition experiments using Triton X-114. Analysis of hydrolytic products indicated $p 68 / 70$ to be a glycoprotein, containing $11 \%$ carbohydrate. Key Words: Goldfish-Glycoprotein-Plasma membrane-Regeneration-Optic nerve.

J. Neurochem. 62, 1182-1191 (1994).
\end{abstract}

The goldfish visual projection provides a useful model in which to study nerve regeneration in the CNS. When the optic nerve is cut, the severed axons from the retinal ganglion cells (RGCs) grow out, reforming their contacts with the optic tectum (Sperry, 1963). Regeneration of RGC axons can be verified experimentally by morphological (Grafstein and McQuarrie, 1978) and biochemical changes (Agranoff et al., 1980), as well as by recovery of vision. Because optic nerve and other intrinsic CNS fibers of warm-blooded vertebrates do not share this ability to restore function, the details of the recovery process in both warm- and cold-blooded vertebrates have been investigated extensively.

Our laboratory has been studying two proteins, termed $\mathrm{p} 68 / 70$, that were found to be synthesized at elevated levels during regeneration of the goldfish op- tic nerve (Heacock and Agranoff, 1982). This doublet, purified from goldfish brain, is here termed p68/70. A polyclonal antibody to $\mathrm{p} 68 / 70$ has established immunoreactive material in all goldfish tissues tested, with highest levels found in brain, egg, and ovary (Wilmot et al., 1993). p68/70 is axonally transported with the slow component (Heacock and Agranoff, 1982; Perry et al., 1985). Immunocytochemical studies of retinal explants from postcrush fish (i.e., fish in which the optic nerve had been crushed, and undergoing regeneration) indicate $p 68 / 70$ to be enriched in axonal varicosities and growth cones (Wilmot et al., 1993). The increased expression of this protein during regeneration and the intense immunolabeling observed in areas known to mediate cellular growth in the goldfish suggest p68/70 plays a role not only in axonal regrowth, but in neural development as well (Wilmot et al., 1993).

The development of a scheme to purify goldfish p68/70 to homogeneity from a soluble brain fraction has allowed us to further biochemically characterize these proteins. The results indicate p68/70 to be a highly elongated protein dimer associated with the plasma membrane, as well as with the cytosolic fraction of goldfish brain homogenate. In addition, p68/ 70 was found to be a glycoprotein, a finding that likely explains some of the previously observed properties of the doublet (Wilmot et al., 1993).

\section{MATERIALS AND METHODS}

\section{Materials}

TSK-3000SW and TSK-4000SW columns and HT-hydroxylapatite were obtained from Bio-Rad (Richmond, CA,

Received March 31, 1993; revised manuscript received August 3, 1993; accepted August 9, 1993.

Address correspondence and reprint requests to Dr. B. W. Agranoff at Neuroscience Laboratory Building, University of Michigan, 1103 East Huron, Ann Arbor, MI 48104-1687, U.S.A.

Abbreviations used: IDA, iminodiacetic acid; LDH, lactate dehydrogenase; RGC, retinal ganglion cell; $R_{\mathrm{s}}$, Stokes radius; $s_{20, w}$, sedimentation coefficient; $S D H$, succinate dehydrogenase; SDS-PAGE, sodium dodecyl sulfate-polyacrylamide gel electrophoresis. 
U.S.A.). The Mono P HR 5/20 column and Polybuffer 74 were the products of Pharmacia (Piscataway, NJ, U.S.A.). Goat anti-rabbit ${ }^{125} \mathrm{I}-\mathrm{IgG}$ was purchased from ICN Biomedicals (Irvine, CA, U.S.A.). Goat anti-rabbit IgG horseradish peroxidase conjugate was obtained from GIBCO BRL (Gaithersburg, MD, U.S.A.). S \& S NC nitrocellulose was purchased from Schleicher \& Schuell (Keene, NH, U.S.A.). The DIG glycan differentiation kit and glycosidases were from Boehringer Mannheim Corp. (Indianapolis, IN, U.S.A.). Trifluoromethanesulfonic acid and anisole were purchased from Aldrich Chemical Co. (Milwaukee, WI, U.S.A.). DEAE-Sephacel, iminodiacetic acid (IDA) agarose, Sephadex G-50, protein standards, molecular weight markers and all other chemicals were from Sigma Chemical Co. (St. Louis, MO, U.S.A.).

\section{Animals}

Goldfish, 3-4 in. in length, were purchased from Grassy Forks Fisheries, Martinsville, IN, U.S.A. They were maintained at $25^{\circ} \mathrm{C}$ in 50 -gal tanks before use.

\section{Purification of p68/70 from goldfish brains}

Buffers used were as follows: A, $20 \mathrm{~m} M$ HEPES (pH 7.0) containing $0.32 M$ sucrose, $10 \mathrm{~m} M$ EDTA, and $1 \mathrm{~m} M$ phenylmethylsulfonyl fluoride; $\mathrm{B}, 20 \mathrm{~m} M$ sodium acetate $(\mathrm{pH}$ 5.2) containing $1 \mathrm{~m} M$ EDTA; C, $20 \mathrm{~m} M$ sodium acetate (pH 4.2) containing $1 \mathrm{~m} M$ EDTA; D, $20 \mathrm{~m} M$ sodium acetate (pH 4.2) containing $100 \mathrm{~m} M \mathrm{NaCl}$ and $1 \mathrm{~m} M$ EDTA; E, $20 \mathrm{~m} M$ Tris- $\mathrm{HCl}$ (pH 8.3) containing $100 \mathrm{~m} M \mathrm{NaCl}$; and $\mathrm{F}, 20 \mathrm{mMNaH} \mathrm{PO}_{4}$ (pH 6.0) containing $200 \mathrm{mM} \mathrm{NaCl}, 0.1$ $\mathrm{m} M$ EDTA, and $0.01 \%$ azide.

Brains were homogenized in 5 volumes (wt/vol) of icecold buffer A using 10 strokes of a Teflon-on-glass Dounce homogenizer. The remaining steps were performed at $4{ }^{\circ} \mathrm{C}$. The homogenate was centrifuged for $20 \mathrm{~min}$ at $10,000 \mathrm{~g}$. The pellet was resuspended in 5 volumes of buffer $A$ and recentrifuged. The combined supernatants were centrifuged for $60 \mathrm{~min}$ at $100,000 \mathrm{~g}$. The high-speed supernatant was dialyzed against $4 \mathrm{~L}$ of buffer $\mathrm{B}$, with one change. The sample was then centrifuged for $20 \mathrm{~min}$ at $38,000 \mathrm{~g}$, and the supernatant was applied to a $2.2 \times 10-\mathrm{cm}$ column of DEAESephacel, equilibrated in buffer $\mathrm{B}$, at a flow rate of $2 \mathrm{ml}$ / min. This and subsequent chromatographic procedures were performed using an LKB HPLC system (Pharmacia) equipped with a 2158 Uvicord SD detector and a 2220 recording integrator. For large-scale operations, a peristaltic pump was used to load samples. The column was washed with 2 volumes of buffer B, 2 volumes of buffer $C$, and then with buffer $D$ until the main protein peak had eluted. p68/ 70 was detected in this and subsequent chromatographic separations using western analysis quantitated by means of a ${ }^{125} \mathrm{I}$-labeled goat anti-rabbit antibody (Wilmot et al., 1993). Fractions $(10 \mathrm{ml})$ containing p68/70 were combined and dialyzed against $4 \mathrm{~L}$ of buffer $\mathrm{E}$ for 2 days, with three changes. This sample was applied to a $2.2 \times 15-\mathrm{cm}$ column of IDA agarose charged to $80 \%$ capacity with cupric chloride $\left(\mathrm{Cu}^{2+}-\mathrm{IDA}\right.$ agarose column), at a flow rate of $0.5 \mathrm{ml}$ / min. Ten-milliliter fractions were collected, and those enriched in p68/70 were combined (typically for a final volume of $100 \mathrm{ml}$ ), made $10 \mathrm{~m} M$ in EDTA by addition of $1 / 9$ volume of $100 \mathrm{~m} M$ EDTA ( $\mathrm{pH} 7.0$ ), and concentrated to 1 $\mathrm{ml}$ using an Amicon concentrator equipped with a PM 10 membrane (Amicon Corp., Danvers, MA, U.S.A.). Aliquots of $100 \mu \mathrm{l}$ were applied to an $8 \times 300-\mathrm{mm}$ TSK$3000 \mathrm{SW}$ column equilibrated in buffer $\mathrm{F}$, at a flow rate of
$0.5 \mathrm{ml} / \mathrm{min}$. Fractions of five drops were collected. Tubes containing p $68 / 70$ were combined and stored at $-70^{\circ} \mathrm{C}$. Relatively large amounts of p68/70-like proteins could be purified from the eggs of carp (Cyprinus carpio) and goldfish by addition of a HT-hydroxylapatite column step after the $\mathrm{Cu}^{2+}$-IDA agarose column.

The method used to purify essentially $p 68$-free $p 70$ was a modification of the above procedure in which the highspeed supernatant was brought to $\mathrm{pH} 5$ with $1 \mathrm{M}$ acetic acid, stirred at $4^{\circ} \mathrm{C}$ for $1.5 \mathrm{~h}$, and then centrifuged at $10,000 \mathrm{~g}$ for $20 \mathrm{~min}$. The procedure used to purify p68/70 was followed from this point.

\section{Determination of Stokes radius $\left(\boldsymbol{R}_{\mathrm{s}}\right)$}

A $7.5 \times 300-\mathrm{mm}$ Ultropac TSK-4000SW column was equilibrated in buffer $\mathrm{F}$ at $4^{\circ} \mathrm{C}$, and $100-\mu 1$ ( $200 \mu \mathrm{g}$ of protein) samples were applied. The column was eluted at a flow rate of $0.5 \mathrm{ml} / \mathrm{min}$. The void and total volume were determined using salmon sperm DNA and potassium dichromate, respectively. Standards used were bovine thyroglobulin $\left(R_{\mathrm{s}}=8.6 \mathrm{~nm}\right)$, bovine gamma globulin $\left(R_{\mathrm{s}}=5.1 \mathrm{~nm}\right)$, chicken ovalbumin $\left(R_{\mathrm{s}}=2.8 \mathrm{~nm}\right)$, and horse myoglobulin $\left(R_{\mathrm{s}}=1.9 \mathrm{~nm}\right)$. The Stokes radius of $\mathrm{p} 68 / 70$ was determined as described by Laurent and Killander (1964) from the linear plot of the Stokes radius versus $\left(-\log K_{\mathrm{av}}\right)^{1 / 2}$ (Siegel and Monty, 1966).

\section{Determination of sedimentation coefficients $\left(s_{20, w}\right)$}

Linear sucrose gradients $(2-10 \%, \mathrm{wt} / \mathrm{vol})$ were prepared in either $\mathrm{H}_{2} \mathrm{O}$ or $\mathrm{D}_{2} \mathrm{O}$ by means of a two-chamber gradient mixer. After the sample, in buffer $F$, was layered on top of the gradient, centrifugation was performed in an SW Ti40 rotor at $40,000 \mathrm{rpm}$ for $14 \mathrm{~h}$ at $4^{\circ} \mathrm{C}$. Fractions $(0.5 \mathrm{ml})$ were collected by pumping buffer from the bottom of the tube, at a flow rate of $0.5 \mathrm{ml} / \mathrm{min}$. Standard proteins were run together with p68/70. Samples of $50 \mu$ l were applied to $10 \%$ sodium dodecyl sulfate-polyacrylamide gel electrophoresis (SDS-PAGE; Laemmli, 1970). The gel was then stained with Coomassie Brilliant Blue (G-250) and the density of the individual bands was determined using a microcomputer-assisted densitometer (Dell Computer Corp., Austin, TX, U.S.A.). The elution position for each protein from the gradient was determined from a plot of the band density versus tube number. For membrane-bound p68/70, plasma membrane proteins were solubilized in $1 \% \beta$-octyl glucoside and applied to gradients containing $1 \%$ of the detergent. For membrane-bound p68/70, detection was by quantitative western analysis. Standards used were cytochrome $c\left(s_{20, w}\right.$ $=1.9$ ), ovalbumin $\left(s_{20, w}=3.55\right)$, bovine serum albumin $\left(s_{20, w}=4.6\right)$, and $\operatorname{IgG}\left(s_{20, w}=7.2\right)$. The sedimentation coefficient of p68/70 was determined as described by Martin and Ames (1961).

\section{Calculation of the physical properties of $\mathrm{p} 68 / 70$}

From the Stokes radius and sedimentation coefficient, the molecular weight of p68/70 in solution was calculated by the formula $\mathrm{M}_{\mathbf{r}}=R_{\mathrm{s}} \times 4,240 \times s_{20, w}$ (Siegel and Monty, 1966). The frictional ratio was calculated from $f / f_{0}=1.393$ $\left(R_{\mathrm{s}} / \mathrm{M}_{\mathrm{r}}^{-3}\right)$, assuming a solvation factor of $0.2 \mathrm{~g} / \mathrm{g}$ of protein and a partial specific volume of $0.735 \mathrm{~cm}^{3} / \mathrm{g}$ (Sherman, 1975). The axial ratio was calculated, assuming the shape of a prolate ellipsoid, using the equation $F=f / f_{\mathrm{sph}}=\left(1-p^{2}\right)^{1 / 2} /$ $p^{2 / 3} \ln \left\{\left[1+\left(1-p^{2}\right)^{1 / 2}\right] / p\right\}$ (Cantor and Schimmel, 1980).

\section{Chromatofocusing}

Chromatofocusing was performed by means of a Pharmacia Mono P HR 5/20 column. The column was equili- 
brated in $25 \mathrm{mM}$ methylpiperazine-HCl buffer ( $\mathrm{pH} 5.7$ ), containing $1 \mathrm{~m} M$ EDTA and $5 M$ urea. p68/70 in buffer $F$ was made $5 M$ in urea and applied to the column, which was then washed with $5 \mathrm{ml}$ of equilibration buffer, followed by Polybuffer 74 (pH 4.0), containing $1 \mathrm{~m} M$ EDTA and $5 M$ urea, at a flow rate of $0.5 \mathrm{ml} / \mathrm{min}$. Fractions of five drops were collected and monitored by SDS-PAGE.

\section{Membrane extraction}

Synaptic plasma membranes were prepared as described by Sun et al. (1988) and stored at $-70^{\circ} \mathrm{C}$. Before use the thawed membranes were pelleted at $38,800 \mathrm{~g}$ for $20 \mathrm{~min}$ and resuspended at a concentration of $2 \mathrm{mg} / \mathrm{ml}$ of protein in 10 $\mathrm{m} M$ HEPES-HCl buffer ( $\mathrm{pH} 7.0$ ) containing $1 \mathrm{~m} M$ EDTA, $2 \mathrm{~m} M$ phenylmethylsulfonyl fluoride, and $20 \mathrm{~m} M$ leupeptin (control buffer). For extraction studies, $100 \mu \mathrm{l}$ of this suspension was mixed with $100 \mu \mathrm{l}$ of $2 \times$ extraction buffer. Final buffer concentrations used for extraction were as fol-

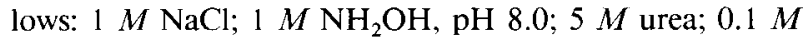
$\mathrm{Na}_{2} \mathrm{CO}_{3}, \mathrm{pH} 11.0$; and $1 \%$ Triton X-100. With the exception of the $0.1 M \mathrm{Na}_{2} \mathrm{CO}_{3}$, all were in control buffer. After $30 \mathrm{~min}$ at $4^{\circ} \mathrm{C}$, the samples were centrifuged at $100,000 \mathrm{~g}$ for $30 \mathrm{~min}$. The supernatant was removed and made $400 \mu \mathrm{l}$ with SDS-PAGE gel sample buffer. The pellet was resuspended in $200 \mu \mathrm{l}$ of control buffer and $200 \mu \mathrm{l}$ of SDS-PAGE gel sample buffer. $p 68 / 70$ concentration was determined by quantitative western analysis. Levels of p68/70 were calculated as the percentage of distribution of $p 68 / 70$ between the supernatant and the pellet, and as the total recovery (supernatant and pellet) for a given treatment versus the control.

\section{Phase partition}

The procedure of Bordier (1981) was followed. Both membrane-bound and soluble p68/70 were tested. Synaptic plasma membranes were resuspended in $20 \mathrm{mM}$ Tris- $\mathrm{HCl}$ (pH 7.4) containing $100 \mathrm{~m} M \mathrm{NaCl}, 0.01 \%$ azide, $1 \mathrm{~m} M$ EDTA, and $10 \mu M$ leupeptin (TBS with inhibitors) to make $1 \mathrm{mg} / \mathrm{ml}$ of protein. A $20 \mu \mathrm{g} / \mathrm{ml}$ sample of $\mathrm{p} 68 / 70$, which had been purified from cytosol, was used to test soluble p68/70. The concentration of $p 68 / 70$ was determined by quantitative western assay. The effects of phosphatidylethanolamine, phosphatidic acid, phosphatidylcholine, phosphatidylserine, and cholesterol on phase partitioning were tested by making the sample buffer $0.1 \%$ in the respective phospholipid or cholesterol. To test the effects of metal ions, the sample buffer was made both $5 \mathrm{mM}$ in $\mathrm{Mg}^{2+}$ and $\mathrm{Ca}^{2+}$.

Sequential phase partitioning was performed by a modification of the above procedure. Synaptic plasma membranes were resuspended in TBS with inhibitors to make the final protein concentration $1 \mathrm{mg} / \mathrm{ml}$. This sample was made $1 \%$ (wt/vol) with respect to Triton X-114 and placed on ice for 5 min. Phase separation was effected by incubation at $30^{\circ} \mathrm{C}$ for $3 \mathrm{~min}$. The phases were separated by centrifugation for 1 min in a microfuge at $5,000 \mathrm{rpm}$. A sucrose cushion was not used. The supernatant was removed and placed in an Eppendorf tube, and $55 \mu \mathrm{l}$ of $10 \%$ Triton X-114 added. The pellet was resuspended in $0.5 \mathrm{ml}$ of TBS with protease inhibitors, and $5 \mu$ of $10 \%$ Triton X-114 was added. Both samples were placed on ice for $5 \mathrm{~min}$, and the separation was repeated. This procedure was repeated six times, with the supernatant from each tube being transferred to the pellet of the next. The final samples were adjusted to contain identical amounts of detergent and buffer by addition of $55 \mu \mathrm{l}$ of $10 \%$ Triton X-114 to tube 8 (the final supernatant), and 0.5 $\mathrm{ml}$ of TBS to tube 1 (the starting tube). Fractions of $50 \mu 1$ were assayed by western analysis. For this experiment, a goat anti-rabbit IgG horseradish peroxidase conjugate was used in place of the goat anti-rabbit ${ }^{125} \mathrm{I}-\mathrm{IgG}$. Bands were visualized by incubation of the nitrocellulose sheet in $50 \mathrm{ml}$ of reaction buffer, which consisted of $20 \mathrm{~m} M$ Tris- $\mathrm{HCl}$ ( $\mathrm{pH}$ 7.4) containing $20 \%$ ( $\mathrm{vol} / \mathrm{vol}$ ) methanol, $100 \mathrm{mM} \mathrm{NaCl}$, $0.05 \%$ ( $\mathrm{vol} / \mathrm{vol})$ of $30 \%$ hydrogen peroxide solution, and $0.06 \%$ (wt/vol) 4-chloro-1-naphthol.

\section{Subcellular localization}

The procedure of Sun et al. (1988) was adapted to prepare subcellular fractions from goldfish brain. Approximately 10 $\mathrm{g}$ of tissue ( 125 goldfish brains) was used to prepare the subcellular fractions, which were stored at $4^{\circ} \mathrm{C}$ and assayed within $24 \mathrm{~h}$. Marker enzymes used were as follows: for microsomes, aryl esterase (Shephard and Hubscher, 1969); for plasma membrane, 5'-nucleotidase (Anner and Moosmayer, 1975); for mitochondria, succinate dehydrogenase (SDH) (Sottocasa et al., 1967); and for cytosol, lactate dehydrogenase (LDH) (Johnson and Whittaker, 1963). For p68/ 70 determinations, fractions were stored at $-70^{\circ} \mathrm{C}$, and the doublet was quantitated by western analysis. Results for each marker enzyme are plotted as the relative specific activity found in each subcellular fraction, with p68/70 reported as the relative specific concentration. In each instance, the relative specific activity is defined as the percentage of activity of a marker enzyme recovered in a fraction divided by the percentage of protein recovered in that fraction, whereas the relative specific concentration is the percentage of $\mathrm{p} 68$ / 70 by weight recovered in a fraction divided by the percentage of protein recovered in that fraction. The relative specific activity and concentration of the homogenate is defined as 1.0 .

\section{Preparation of membrane skeletons}

Detergent-insoluble membrane skeletons were prepared from plasma membrane following the procedure of Moss (1983). Fractions were dialyzed overnight against $1 \mathrm{~L}$ of 10 $\mathrm{m} M$ Tris (pH 7.6), with $2 \mathrm{~m} M$ EDTA, $0.02 \%$ sodium azide, and analyzed by SDS-PAGE and western analysis.

\section{Amino acid and carbohydrate analysis}

Vapor hydrolysis $(75 \mathrm{~min}$ in $6 \mathrm{M} \mathrm{HCl}$ ) of proteins and preparation of the phenylisothiocyanate amino acid derivatives was performed on an ABI model $420 \mathrm{H}$ amino acid derivatizer. HPLC analysis of the derivatized amino acids was performed using an ABI model $130 \mathrm{~A}$ microseparation system. No correction was made for losses due to the hydrolysis. For sialic acid determination, samples were hydrolyzed in $0.1 \mathrm{M} \mathrm{HCl}$ for $1 \mathrm{~h}$ at $80^{\circ} \mathrm{C}$. For determination of all other monosaccharides, samples were hydrolyzed in $2 \mathrm{M}$ trifluoroacetic acid for $5 \mathrm{~h}$ at $100^{\circ} \mathrm{C}$. Aliquots were analyzed amperometrically on a Dionex BioLC instrument (Sunnyvale, CA, U.S.A.) using a Carbopac PAl anion-exchange column. An isocratic gradient of $90 \%$ water $/ 10 \% 200 \mathrm{mM}$ sodium hydroxide was used to elute neutral and amino monosaccharides, whereas a gradient from $80 \%: 10 \%: 10 \%$ to $75 \%: 10 \%: 15 \%$ water $/ 200 \mathrm{~m} M \mathrm{NaOH} / 1 M \mathrm{NaOH}$ was used to elute sialic acid. Neutral sugars were also determined using the method of Hodge and Hofreiter (1962). The ratio of amino to neutral sugars, 0.65 , was in reasonable agreement with that obtained by an alternative method, in which amino sugar content estimated from the amino acid analy- 
sis $(4.8 \%)$ was compared with neutral sugar content determined with phenol-sulfuric acid $(6.08 \%)$, ratio 0.79 .

\section{Lectin binding}

The affinity of different lectins for p68/70 was tested on Ouchterlony plates and the DIG glycan differentiation kit. For the immunodiffusion experiments, plates of $1 \%$ agar in $20 \mathrm{~m} M$ phosphate buffer (pH 7.0) containing $150 \mathrm{mM}$ $\mathrm{NaCl}$, and $10 \mu \mathrm{M} \mathrm{MgCl}_{2}$ were used. The sample, containing $25 \mu \mathrm{g}$ of p68/70 in $50 \mu \mathrm{l}$, was placed in the center of a seven-well plate, and the lectin solutions $(0.5 \mathrm{mg} / \mathrm{ml})$ were added to the peripheral wells. Plates were incubated at room temperature overnight. Lectins used (the gift of Dr. Irwin Goldstein) were from Amaranthus caudatus, which recognizes $\mathrm{Gal}(\beta 1-3)-\mathrm{GalNac}$; Galanthus nivalis, which recognizes terminal mannose; Maakia amurensis, which recognizes sialic acid-linked $\alpha(2-3)$ to galactose; Sambucus nigra, which recognizes sialic acid-linked $\alpha(2-6)$ to galactose; Ulex europaeus, which recognizes $\alpha$-L-fucose; and wheat germ, which recognizes GlcNac residues in $\beta 1-4$ linkage. For the DIG glycan differentiation kit, $1 \mu \mathrm{g}$ of p68/70 was applied to SDS-PAGE and electrotransferred to nitrocellulose. Digoxigenin-labeled lectins used recognize terminal mannose ( $G$. nivalis), sialic acid-linked $\alpha(2-3)$ to galactose (M. amurensis), sialic acid-linked $\alpha(2-6)$ to galactose $(S$. nigra), Gal $\beta$ (1-3)-GalNac (A. caudatus), and $\operatorname{Gal} \beta(1-3)$ GlcNac (from Datura stramonium). Control proteins were tested for each lectin.

\section{Periodate oxidation/borohydride reduction of p68/70}

Lyophilized p68/70 (1 mg) was taken up in $1 \mathrm{ml}$ of 100 $\mathrm{m} M$ sodium acetate buffer $(\mathrm{pH} 4.5)$, containing $25 \mathrm{~m} M$ sodium metaperiodate, and reacted in the dark for $24 \mathrm{~h}$ at room temperature. The sample was dialyzed against 100 $\mathrm{m} M$ boric acid ( $\mathrm{pH} 8.0$ ) in the dark overnight. Sodium borohydride was then added to make the sample $100 \mathrm{mM}$, and the reaction allowed to proceed for $24 \mathrm{~h}$ in the dark at $4{ }^{\circ} \mathrm{C}$. The reactivity of this sample and untreated p68/70 toward the affinity-purified anti-p68/70 IgG was determined by spotting $2 \mu \mathrm{l}$ of a serial dilution of the doublet, made in 20 $\mathrm{m} M$ Tris- $\mathrm{HCl}$ (pH 7.4), containing $150 \mathrm{~m} M \mathrm{NaCl}$ and 50 $\mu \mathrm{g} / \mathrm{ml}$ of bovine serum albumin, onto nitrocellulose. Spots were visually compared with that of a progressive dilution series $(1: 2)$ of $\mathrm{p} 68 / 70$ samples that were not subjected to the above treatment. The western analysis in this experiment used a goat anti-rabbit $\mathrm{IgG}$ horseradish peroxidase conjugate. Blots were visualized by incubation in $50 \mathrm{ml}$ of reaction buffer, which consisted of $20 \mathrm{~m} M$ Tris- $\mathrm{HCl}(\mathrm{pH} 7.4$ ), containing $20 \%$ (vol/vol) methanol, $100 \mathrm{~m} M \mathrm{NaCl}, 0.05 \%$ (vol/vol) of $30 \%$ hydrogen peroxide solution, and $0.06 \%$ (wt/vol) 4-chloro-1-naphthol.

\section{Miscellaneous techniques}

Protein was determined by the method of Bradford (1976) using bovine serum albumin as a standard. Inorganic phosphate was determined using the method of Bartlett (1959). Trifluoromethanesulfonic acid treatment of p68/70 was performed as described by Edge et al. (1981).

\section{RESULTS}

\section{Purification of p68/70}

The results of the purification procedure for the doublet from goldfish brain are shown in Table 1. p68/70 was purified 887 -fold, from which it can be extrapolated that the doublet constitutes $0.11 \%$ of total brain protein. The elution profiles for each of the chromatographic separations are shown in Fig. 1. Purification to homogeneity was achieved, as judged by SDS-PAGE (Fig. 2). The $\mathrm{Cu}^{2+}$-IDA agarose column step resulted in the greatest purification, bringing p68/70 to near homogeneity. Two remaining contaminating proteins of apparent molecular masses of 28 and $26 \mathrm{kDa}$ were then removed by TSK-3000SW chromatography.

\section{Amino acid and carbohydrate analysis}

The amino acid composition of p68/70 is shown in Table 2. Glutamate and proline values were high and the arginine value was low, compared with a table of typical amino acid compositions of proteins (Creighton, 1984). The inability of the affinity-purified anti-p68/70 antibody to recognize proteins outside of the Cyprinidae family (Wilmot et al., 1993), or to identify a positive clone in immunoscreening a goldfish retinal 10-day postcrush retinal $\lambda$ gt 11 expression library (not shown), suggests that the antibody is directed against a carbohydrate substituent present in the isolated doublet. The ability of the affinity-purified anti-p68/70 IgG to bind to p68/70 was reduced by an average of $75 \%$ based on comparison of three independent western dilution series (see Materials and Methods) after periodate oxidation/borohydride reduction, a result that supports the hypothesis that carbohydrates contribute significantly to the antigenicity of the doublet. On the basis of comparison with authentic standards, the relative amounts of the following monosaccharides were identified as follows: fucose, 1.0; glucosamine, 1.0; galactose, 0.9 ; galactosamine, 0.4; and mannose, 0.3 .

\section{Physical properties of p68/70}

Although p68/70 migrated with apparent molecular masses of 68-70 kDa during SDS-PAGE, the elution position of the doublet from gel filtration columns suggests that the native protein has a molecular mass of $\sim 200 \mathrm{kDa}$. We therefore examined further the physical properties of undenatured $\mathrm{p} 68 / 70$. The Stokes radius of p68/70 was determined to be $5.8 \mathrm{~nm}$ (Fig. 3A), and the sedimentation coefficient was found to be 5.2 (Fig. 3B). We also determined the sedimentation coefficient to be 5.15 in $\mathrm{D}_{2} \mathrm{O}$ (Fig. 3C), indicating that carbohydrate covalently linked to the protein did not significantly affect its density, and that the average partial specific volume for the standard proteins of $0.735 \mathrm{~cm}^{3} / \mathrm{g}$ could be used for $\mathrm{p} 68 / 70$. From the Stokes radius and sedimentation coefficient the molecular mass in solution was found to be 128 $\mathrm{kDa}$, indicating $\mathrm{p} 68 / 70$ is associated as a dimer, in agreement with the chromatofocusing results (see below). The frictional coefficient ratio was determined to be 1.6. The axial ratio was calculated assuming the shape of a prolate ellipsoid and found to be 12:1. 
TABLE 1. Purification of p $68 / 70$ from goldfish brains

\begin{tabular}{lcccc}
\hline \multicolumn{1}{c}{ Sample } & $\begin{array}{c}\text { Protein } \\
(\mathrm{mg})\end{array}$ & $\begin{array}{c}\text { p68/70 } \\
(\mathrm{mg})^{a}\end{array}$ & $\begin{array}{c}\text { Recovery } \\
(\%)\end{array}$ & $\begin{array}{c}\text { Purification } \\
\text { factor }\end{array}$ \\
\hline Homogenate & $6,198 \pm 890$ & $7.0 \pm 1.5$ & 100 & 1.0 \\
High-speed supernatant & $1,763 \pm 354$ & $1.4 \pm 0.3$ & 20.0 & 0.7 \\
pH 5 supernatant & $870 \pm 96$ & $1.2 \pm 0.20$ & 17.1 & 1.2 \\
DEAE-Sephacel & $154 \pm 19$ & $0.89 \pm 0.10$ & 12.7 & 5.1 \\
Cu' & $2.6 \pm 0.7$ & $0.73 \pm 0.12$ & 10.4 & 248 \\
TSK-3000SW & $0.44 \pm 0.09$ & $0.44 \pm 0.09$ & 6.3 & 887 \\
\hline
\end{tabular}

${ }^{a}$ Determined by quantitative western analysis, using the purified preparation (TSK-3000SW eluant) as a standard. Results are mean \pm SEM values of three preparations of 1,000 goldfish brains.

\section{Chromatofocusing}

p68/70 exhibits slightly different isoelectric points for the p68 (5.0) and p70 (4.8) components of the doublet (Heacock and Agranoff, 1982). Therefore, we attempted to separate the two forms on the basis of charge using chromatofocusing. SDS-PAGE of the chromatofocusing column fractions is shown in Fig. 4. Three forms of $\mathrm{p} 68 / 70$ were found, homodimers of 68 and 70 , and a heterodimer of $68 / 70$. Elution order was consistent with the isoelectric points of the individual subunits, with the light homodimer eluting first, the heterodimer next, and the heavy homodimer last. Urea was present during the chromatography to prevent aggregation of $\mathrm{p} 68 / 70$. The chromatofocusing column buffer Polybuffer 74 proved difficult to remove and resulted in poor protein recoveries, precluding its use for preparative purposes.

\section{Subcellular localization}

During purification, a large amount of $\mathrm{p} 68 / 70$ was lost to the particulate fraction in the preparation of the high-speed supernatant fraction (Table 1). In addition, p68/70 was found to have sequence homology to a synaptic vesicle protein. We therefore further investigated the subcellular distribution of the doublet, as shown in Fig. 5. p68/70 was found to have a broad distribution pattern, and appeared to resemble most closely that of $5^{\prime}$-nucleotidase activity, a marker enzyme for plasma membranes $(r=0.79, p<0.05)$, whereas displaying little correlation with the SDH activity $(r=0.17)$, the aryl esterase activity $(r=0.76, p$ $>0.3)$, or the LDH activity $(r=0.48)$, marker enzymes for mitochondria, microsomes, and cytosol, respectively. The plasma membrane fraction had the highest relative specific concentration for p68/70. Aryl esterase activity, a microsomal marker, was more enriched in the goldfish brain plasma membrane fraction than in the microsomal fraction. This unexpected distribution was confirmed by studies with NADPH-cytochrome $c$ reductase (not shown), another marker enzyme for microsomes (Masters et al., 1967). It appears then, that when applied to fish brain, the method used results in a significant contamination of the plasma membrane fraction with microsomal proteins. The recoveries of the marker enzymes used were $96 \pm 3 \%$ for $\mathrm{LDH}, 92 \pm 2 \%$ for aryl esterase,
$77 \pm 9 \%$ for SDH, and $86 \pm 5 \%$ for $5^{\prime}$-nucleotidase. The recovery of p68/70 was $60 \pm 7 \%$. Total protein recovery was $97 \pm 5 \%$.

\section{Membrane extraction}

Membranes were treated with agents known to disrupt specific types of protein-membrane interactions, to investigate the nature of the membrane association observed for p68/70. Results of these studies are shown in Table 3. Treatment with $1 \mathrm{M} \mathrm{NaCl}$ did not extract p68/70 from the membrane fraction, a result militating against association via electrostatic interactions. p68/70 was not extracted by $1 M$ neutral hydroxylamine, a treatment that would cleave the thioester bond formed between fatty acids and cysteine residues. p68/70 was partially extracted from the membrane by high $\mathrm{pH}$, a treatment that cleaves fatty acid-protein oxyester bonds, disrupts the lipid bilayer of the membrane, and perturbs protein-protein interactions. Urea $(5 M)$ treatment, which also should disrupt protein-protein interactions, was found to only partially extract $\mathrm{p} 68 / 70$ from the membrane. Because the sedimentation coefficient of membrane-bound $\mathrm{p} 68 / 70$ was found to be identical to that of the soluble form of $p 68 / 70$, a complex between p68/70 and an integral membrane protein did not appear likely to explain the membrane association. We further investigated the nature of the membrane association of $p 68 / 70$ by analyzing for the presence of the doublet in the plasma membrane skeleton (Moss, 1983). SDS-PAGE and western analysis of the membrane skeleton preparation indicated p68/70 to be present mainly in the soluble fraction, whereas the membrane skeleton is found at the $10-30 \%$ interface under these experimental conditions. p68/70 was totally extracted from the membrane by Triton X-100. Thus, whereas a portion of p68/70 can be extracted from the membrane with urea or high $\mathrm{pH}$ treatment, the doublet appears to be associated with the membrane primarily through hydrophobic interactions, presumably reflecting a substantial stretch of hydrophobic amino acids detected in its primary sequence (Leski et al., 1991).

\section{Phase partition}

Because the membrane extraction experiments indicated p68/70 to be associated with the membrane 

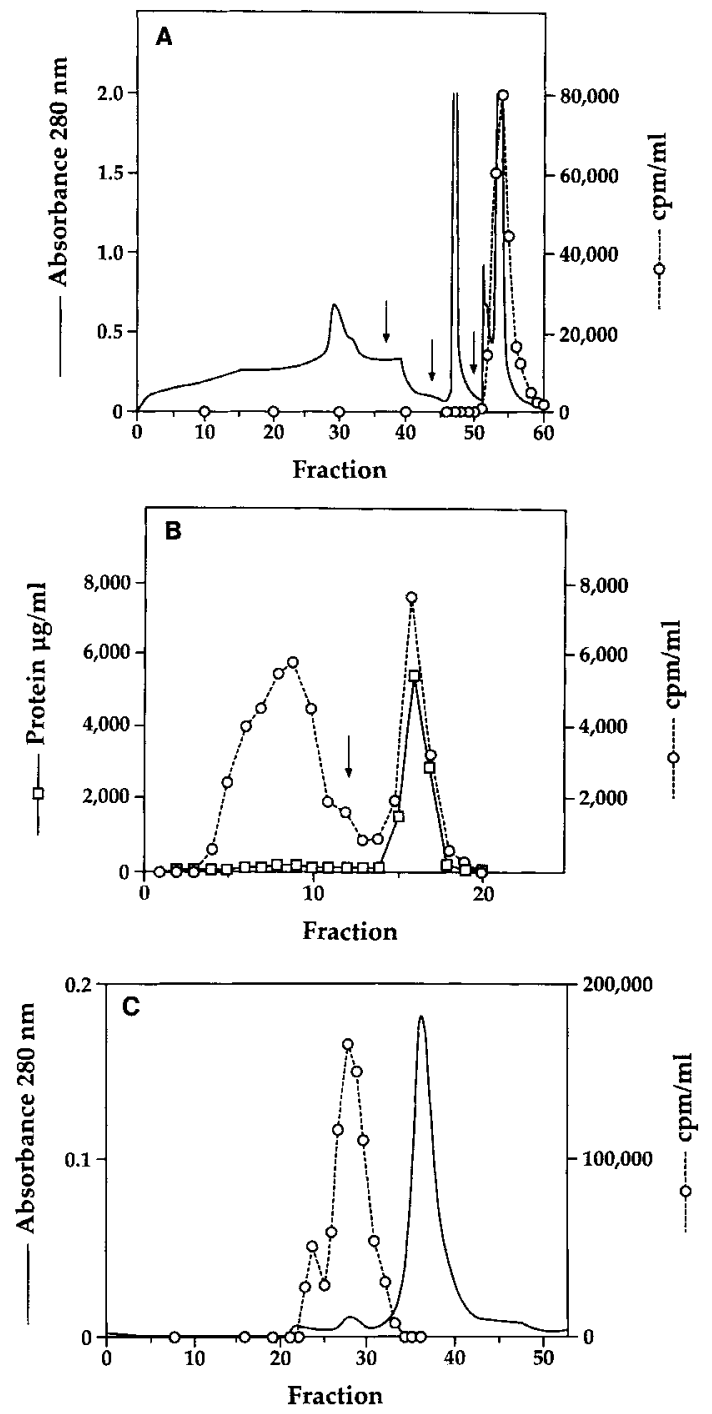

FIG. 1. Purification of $p 68 / 70$ from goldfish brain. A: DEAE-Sephacel chromatography. Arrows (left to right) indicate buffer changes to buffers A, B, and C, respectively. B: Copper affinity chromatography. p68/70 was found largely in the flow-through. The arrow indicates a change in buffer to $0.1 \mathrm{M}$ EDTA, pH 7.0. C: TSK-3000 chromatography. p68/70 eluted primarily in tubes 2831 . The initial minor peak of radioactivity probably contains aggregated p68/70. p68/70 was detected using a western blot assay and plotted as specificaily bound cpm of ${ }^{125}$-GAR IgG bound per milliliter.

through hydrophobic interactions, phase partition experiments were performed to further characterize the membrane association. This experiment takes advantage of the low cloud point of Triton X-114, which is soluble at $4^{\circ} \mathrm{C}$ but forms detergent micelles at $30^{\circ} \mathrm{C}$, which can then be separated from the aqueous phase by centrifugation. Hydrophilic proteins partition into the aqueous phase, whereas hydrophobic proteins insert into the micelles and partition with the detergent phase (Bordier, 1981). Soluble p68/70 partitioned almost entirely $(>97 \%)$ into the aqueous phase. How-

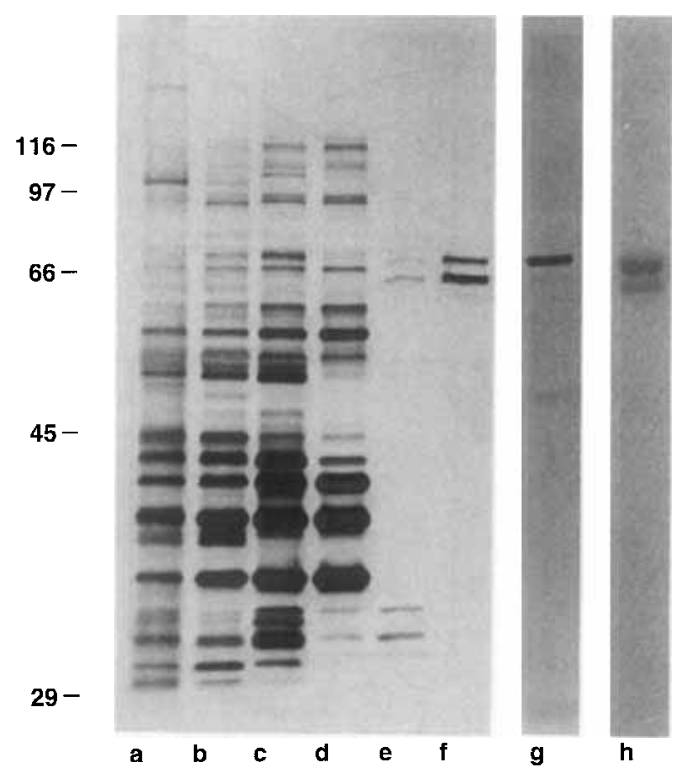

FIG. 2. SDS-PAGE separation of p68/70. Shown are p68/70containing fractions for the brain preparation $(a-f)$, purified brain p70 (g), and carp egg p68/70-like proteins (h). For (a-d) $10 \mu \mathrm{g}$ of protein was applied to the gel, for (e-h) $2 \mu \mathrm{g}$ of protein was applied. Molecular masses ( $\mathrm{kDa}$ ) are indicated on the left. Lane assignments: (a) homogenate; (b) high-speed supernatant; (c) pH 5.2 supernatant; (d) DEAE-Sephacel; (e) $\mathrm{Cu}^{2+}$-IDA agarose column; (f) TSK-3000; (g) brain p70; (h) carp egg p68/70-like proteins. Staining was by silver, except for lane $h$, which was by Coomassie Brilliant Blue.

ever, membrane-bound p68/70 exhibited biphasic properties, with $23 \%$ partitioning into the detergent phase and $77 \%$ into the aqueous phase. No difference was observed for either form when phase partitioning was performed in the presence of phospholipids,

TABLE 2. Amino acid composition of $p 68 / 70$

\begin{tabular}{lc}
\hline Amino acid & $\%(\mathrm{~mol})$ \\
\hline Alanine & 8.9 \\
Arginine & 2.6 \\
Aspartic acid & 8.5 \\
Cysteine & $\mathrm{ND}$ \\
Glutamic acid & 20.5 \\
Glycine & 6.7 \\
Histidine & 0.8 \\
Isoleucine & 2.0 \\
Leucine & 7.7 \\
Lysine & 6.3 \\
Methionine & 0.6 \\
Phenylalanine & 2.9 \\
Proline & 9.4 \\
Serine & 5.7 \\
Threonine & 7.3 \\
Tryptophan & ND \\
Tyrosine & 2.0 \\
Valine & 5.9 \\
\hline
\end{tabular}

ND, not determined. 
A

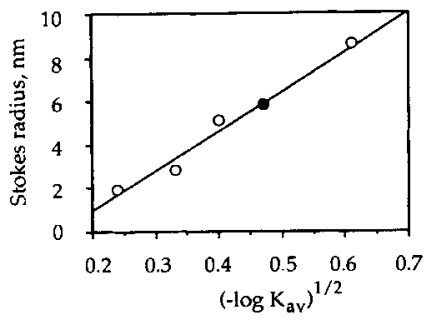

B

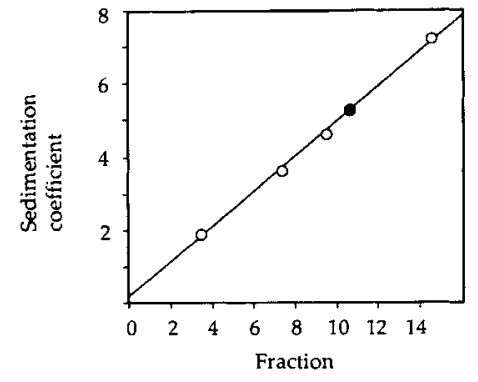

C

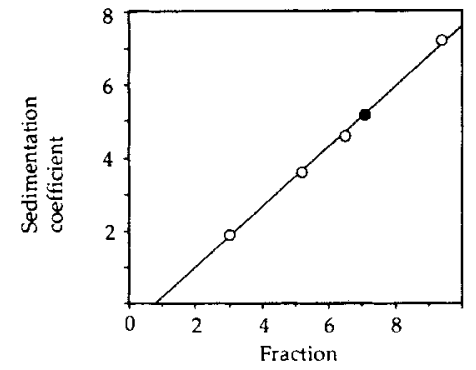

FIG. 3. Determination of the Stokes radius and sedimentation coefficient of p68/70. A: The plot used to determine the Stokes radius. A Stokes radius of $5.8 \mathrm{~nm}$ was found for p68/70. For sedimentation coefficient determinations, $2-10 \%$ gradients of sucrose in buffer $\mathrm{F}$ in either $\mathrm{H}_{2} \mathrm{O}(\mathrm{B})$ or $\mathrm{D}_{2} \mathrm{O}(\mathrm{C})$ were used. Detergent-solubilized membrane-bound $p 68 / 70$ was found to have a sedimentation coefficient of 5.2 in $\mathrm{H}_{2} \mathrm{O}$ (not shown). Filled circles, p68/70; open circles, standard proteins (see text).

metal ions, or EDTA. Inferences from these experiments of distinct forms of $\mathrm{p} 68 / 70$ were not supported by a sequential phase partitioning experiment. Reduction of micelle rigidity by the addition of linoleic acid (Maher and Singer, 1985) had no effect on the distribution of the doublet.

\section{Lectin binding}

The nature of the glycoprotein was further investigated by the use of lectins. Wheat germ agglutinin was found to react very strongly with p68/70 (Fig. 6), which indicated the presence of $\beta$-D-GlcNac(1-4)- $\beta$ $\mathrm{D}-\mathrm{GlcNac}$ in the protein. Treatment of $\mathrm{p} 68 / 70$ with trifluoromethanesulfonic acid to remove covalently bound carbohydrates eliminated this reactivity. Lectins that recognize the $\mathrm{N}$-linkage site or the core disaccharide of O-linked glycoprotein, fucose, terminal mannose, or sialic acid were found not to precipitate p68/70. No reactivity for digoxigenin-labeled lectins toward p68/70 was observed.

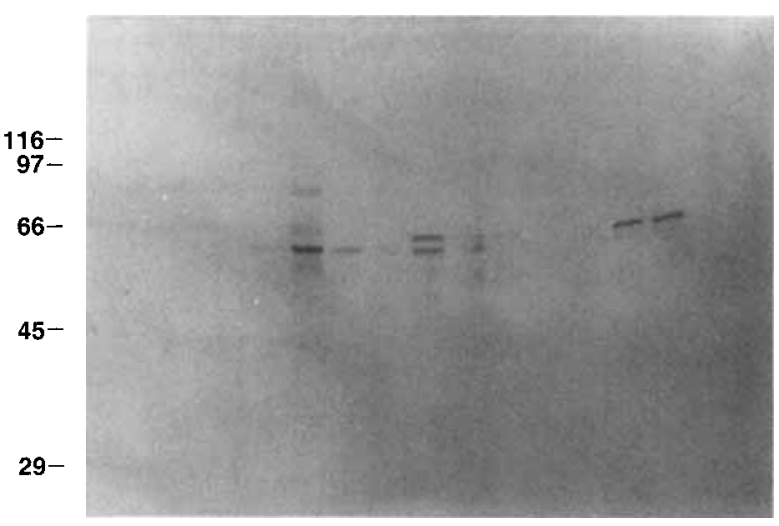

$\begin{array}{lllllllllllllllll}42 & 43 & 44 & 45 & 46 & 47 & 48 & 49 & 50 & 51 & 52 & 53 & 54 & 55 & 56 & 58 & 60\end{array}$

FIG. 4. SDS-PAGE of chromatofocusing fractions. Approximately $100 \mu \mathrm{g}$ of p68/70 was applied to the column. Samples of $50 \mu \mathrm{l}$ were analyzed by SDS-PAGE. The doublet was resolved into three dimeric forms (p68, p68/70, and p70), which eluted from the column as predicted from the isoelectric points of the components. p68 homodimer eluted in tubes 47 and 48 , p68/70 heterodimer eluted in tubes 50 and 51 , and p70 homodimer eluted in tubes 55 and 56 . Molecular masses $(\mathrm{kDa})$ are indicated on the left. Fraction numbers are shown at the bottom of the figure. The gel was stained with silver

\section{DISCUSSION}

The nerve regeneration-associated proteins p68/70, initially identified on the basis of their in vivo labeling in the goldfish visual system (Heacock and Agranoff, 1982), were recently further characterized in regard to their tissue distribution via immunohistochemistry (Wilmot et al., 1993), and in the present study have been purified to homogeneity from goldfish brain homogenates. The purification of $\mathrm{p} 68 / 70$ to homogeneity is largely attributable to the removal of contaminating proteins by means of a $\mathrm{Cu}^{2+}$-IDA agarose column step. Separations using metal chelate affinity chroma-

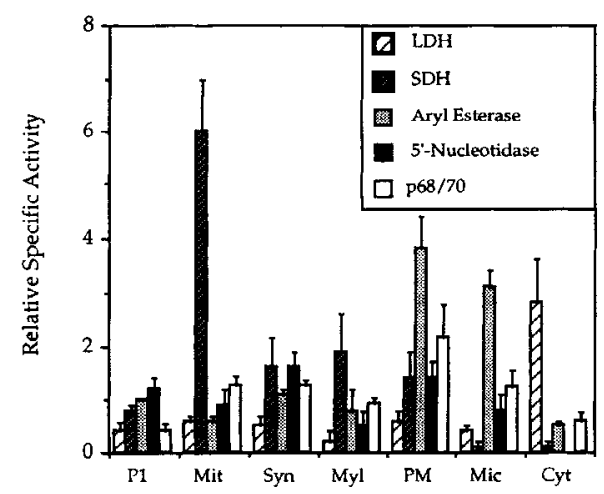

FIG. 5. Subcellular localization of $p 68 / 70$. The location of $p 68 / 70$ was determined by comparing the relative specific activities of marker enzymes for specific organelles versus the relative specific concentration of $p 68 / 70$ in each fraction, prepared as described in the text. The means and standard deviations represent the average of three determinations. 
TABLE 3. Extraction of p68/70 from membranes

\begin{tabular}{|c|c|c|c|c|c|c|}
\hline \multirow[b]{2}{*}{ Sample } & \multicolumn{2}{|c|}{ Supernatant } & \multicolumn{2}{|c|}{ Pellet } & \multicolumn{2}{|c|}{ Recovery } \\
\hline & ng & $\%$ & $\mathrm{ng}$ & $\%$ & ng & $\%$ \\
\hline Control & $11.0 \pm 3.2$ & 6.2 & $167 \pm 6.8$ & 93.8 & $178 \pm 6$ & 100 \\
\hline $1 M \mathrm{NaCl}$ & $12.9 \pm 3.3$ & 6.5 & $186 \pm 6.1$ & 93.5 & $199 \pm 5$ & 111 \\
\hline $1 M \mathrm{NH}_{2} \mathrm{OH}$ & $14.2 \pm 5.7$ & 7.5 & $173 \pm 4.9$ & 92.5 & $187 \pm 11$ & 105 \\
\hline $5 \mathrm{M}$ urea & $73.3 \pm 34.4$ & 34.3 & $140 \pm 7.1$ & 65.7 & $213 \pm 30$ & 120 \\
\hline $0.1 \mathrm{M} \mathrm{Na}_{2} \mathrm{CO}_{3}$ & $80.0 \pm 13.3$ & 51.0 & $76.7 \pm 14$ & 49.0 & $157 \pm 8.4$ & 88.2 \\
\hline $1 \%$ Triton X-100 & $149 \pm 24.2$ & 100 & 0 & 0 & $149 \pm 24$ & 83.7 \\
\hline
\end{tabular}

Results are mean \pm SEM values of three experiments.

tography take advantage of the complexes formed between histidine and cysteine side chains with metal ions, particularly copper and zinc, in aqueous solutions (Porath et al., 1975). For example, $\mathrm{Cu}^{2+}$-IDA agarose columns have been used to purify a histidinefree protein, the adipocyte lipid binding protein, on the basis of its inability to bind to the column (Xu et al., 1991). The doublet proteins' inability to bind to the $\mathrm{Cu}^{2+}$-IDA agarose column may reflect the somewhat low histidine content of p68/70, or unavailability of its histidine residues to the column matrix. Other factors such as carbohydrate substituents might interfere with binding of the doublet to the column. The elongated nature of $\mathrm{p} 68 / 70$ may be explained to some degree by its high proline and/or its high glutamic acid content (Table 2, presumed to be mainly glutamate on the basis of preliminary sequence data).

Although previous investigations emphasized the study of cytosolic p68/70, the subcellular distribution experiment, using the western assay, demonstrated a substantial fraction to be particulate. The membrane association studies indicate that $\mathrm{p} 68 / 70$ is bound to membrane via hydrophobic interactions, whereas the phase partition experiments suggest the doublet is hydrophilic. Explanations offered for such anomalous behavior include the incompatibility of the mem-

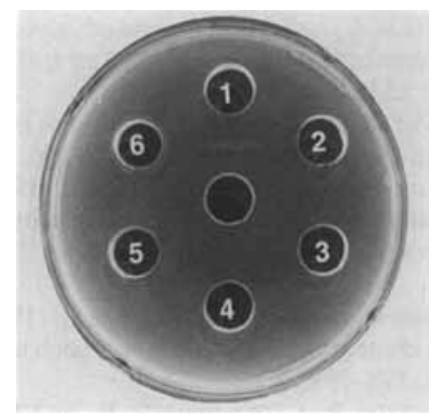

FIG. 6. Ouchterlony analysis of lectin binding. The peripheral wells contained lectins that recognize (1) $\beta$-D-GICNac(1-4)- $\beta$-DGlcNac (wheat germ); (2) sialic acid-Gal( $\beta 1-3)-N$-acetyl GalNac and Gal( $(\beta 1-3)$-GalNac (A. caudatus); $(3)$ terminal mannose (G. nivalis); (4) sialic acid ( $\alpha 2-3)$-Gal $(M$. amurensis); (5) sialic acid ( $\alpha 2-$ $6)$-Gal or sialic acid ( $\alpha 2-6)$-GalNac (S. nigra); and (6) fucose $(U$. europaeus). The center well contained p68/70. brane-spanning region of a protein with the rigid detergent micelles formed by Triton X-114 (Maher and Singer, 1985), the existence of distinct forms of proteins (Swanson et al., 1988), and the presence of hydrophilic substituents on proteins such as carbohydrate chains (Volk and Geiger, 1986). Although we were able to rule out the first two, the possibility that the carbohydrate residues of $\mathrm{p} 68 / 70$ prevent the solubilized doublet from associating with the Triton $\mathrm{X}-114$ micelles in phase partitioning experiments could not be tested, as attempts to denude p68/70 of carbohydrate with glycosidases were not successful.

The cellular function of the doublet is unknown. A 13-residue $\mathrm{CNBr}$ fragment of p68/70 (Leski et al., 1991) was found to have identity with a sequence $\left(\mathrm{M}_{172}-\mathrm{L}_{184}\right)$ in a membrane-spanning region of VAT1, a synaptic vesicle protein of Torpedo (Linial et al., 1989). Although VAT-1 and p68/70 are both derived from teleost nerve tissue, they do not share similar properties, on the basis of the present and of previous studies (Wilmot et al., 1993). The present finding that p68/70 contains carbohydrate may explain a number of previous observations. Whereas the doublet was named on the basis of its apparent molecular mass on $10 \%$ SDS-PAGE, its migration has been found to be anomalous (Wilmot, 1993), probably a reflection of its carbohydrate content (Segrest et al., 1971). The molecular mass of the doublet determined by Ferguson analysis is $53 / 55 \mathrm{kDa}$ (Wilmot et al., 1993). The predicted molecular masses of the protein portion of the glycoconjugate, based on those molecular masses and an $11 \%$ carbohydrate content, would then be $47 /$ $49 \mathrm{kDa}$. A final assignment awaits complete sequencing. p68/70 has not been detected in two-dimensional electrophoretic analysis of in vitro translation products from mRNA isolated from the regenerating goldfish retina (Cauley et al., 1986; Tesser et al., 1986). As these proteins would not be glycosylated, p68/70 apoprotein would migrate at a lower molecular mass. The carbohydrate content may also explain the observed restricted phyletic range of the polyclonal antibody to the Cyprinidae family (Wilmot et al., 1993). Indications that the immunogenicity of the doublet resides largely in the carbohydrate moiety come from the finding that periodate oxidation followed by borohy- 
dride reduction of $\mathrm{p} 68 / 70$ greatly reduces the reaction to the anti-p68/70 antibody. The affinity purification step may have selected for a subpopulation of antibodies in the rabbit antisera that recognizes predominantly the glycan portion of $\mathrm{p} 68 / 70$.

Whether the membrane-bound p68/70 is transported axonally at the rate reported for the cytosolic component has not been fully investigated, although evidence indicating the presence of the doublet in the particulate fraction for the slow component has been reported (Heacock and Agranoff, 1982). It has been suggested that an exchange of a larger soluble nonradiolabeled pool with the smaller radiolabeled membrane-bound state could dilute the radiolabeled form during transport, making it appear to be transported in the slow pool (Wilmot et al., 1993). This may be the case, as p68/70 is found in both the soluble and particulate fractions in goldfish brain homogenates. Another possibility would have p68/70 exchanging with a nonradioactive membrane pool. In retinal explants, p68/70 is found enriched in axonal varicosities (Wilmot et al., 1993). The predominant structural inclusion of these varicosities is a tubular smooth endoplasmic reticulum that is organized in an anastomosing, glomerulus-like arrangement (Koenig et al., 1985). These varicosities are also observed in the regenerating optic nerve in vivo (Murray, 1976). If, in transport to the growth cone, p68/70-containing vesicles were to associate with these varicosities, an exchange of the radiolabeled protein with a larger nonradioactive pool could occur.

Because p68/70 appears to be a component of growing cell types rather than a specific indicator of regeneration in the goldfish (Wilmot et al., 1993), evidence presented in this study suggests that the doublet plays a role in membrane-related events in neuronal cell growth and regrowth. Further understanding of its role will be required to clarify whether $\mathrm{p} 68 / 70$ provides a clue to the ability of cold-blooded vertebrates to regenerate their CNSs.

Acknowledgment: We are indebted to Dr. George Wilmot for furnishing the rabbit anti-p68/70 antibody and contributions to the purification procedure, to Dr. Irwin Goldstein for neutral sugar analyses, to Marianne Lewis for technical assistance, and to Dr. Anne Heacock and Stephanie McWethy for suggestions in the preparation of the manuscript.

\section{REFERENCES}

Agranoff B. W., Feldman E., Heacock A. M., and Schwartz M. (1980) The retina as a biochemical model of central nervous system regeneration. Neurochem. Int 1, 487-500.

Anner B. and Moosmayer M. (1975) Rapid determination of inorganic phosphate in biological systems by a highly sensitive photometric method. Anal. Biochem. 65, 305-309.

Bartlett G. (1959) Phosphorous assay in column fractions. J. Biol. Chem. 234, 466-471.
Bordier C. (1981) Phase separation of integral membrane proteins in Triton X-114 solution. J. Biol. Chem. 256, 1604-1607.

Bradford M. (1976) A rapid and sensitive method for the quantification of microgram quantities of protein utilizing the principle of protein-dye binding. Anal. Biochem. 72, 248-254.

Cantor C. R. and Schimmel P. R. (1980) Biophysical Chemistry, Part II: Techniques for the Study of Biological Structure and Function, p. 561. W. H. Freeman, San Francisco.

Cauley K. A., Sherman T. G., Ford-Holevinski T., and Agranoff B. W. (1986) Rapid expression of novel proteins in goldfish retina following optic nerve crush. Biochem. Biophys. Res. Commun. 138, $1177-1183$.

Creighton T. E. (1984) Proteins, p. 7. W. H. Freeman, New York.

Edge A. S. B., Faltynek C. R., Hof L., Reichert L. E., and Weber P. (1981) Deglycosylation of glycoproteins by trifluoromethanesulfonic acid. Anal. Biochem. 118, 131-137.

Grafstein B. and McQuarrie I. G. (1978) Role of nerve cell body in axonal regeneration, in Neuronal Plasticity (Cotman C. W., ed), pp. 155-195. Raven Press, New York.

Heacock A. M. and Agranoff B. W. (1982) Protein synthesis and transport in the regenerating goldfish system. Neurochem Res. 7, $771-788$.

Hodge J. E. and Hofreiter B. T. (1962) Methods in Carbohydrate Chemistry, Vol. I (Whistler R. L. and Wolfrom M. L., eds), pp. 380-394. Academic Press, New York.

Johnson M. K. and Whittaker V. P. (1963) Lactate dehydrogenase as a cytoplasmic marker in brain. Biochem. J. 88, 404-409.

Koenig E., Kinsman S., Repasky E., and Sultz L. (1985) Rapid mobility of motile varicosities and inclusions contain $\alpha$-spectrin, actin, and calmodulin in regenerating axons in vitro. $J$. Neurosci. 5, 715-729.

Laemmli U. K. (1970) Cleavage of structural proteins during the assembly of the head bacteriophage T4. Nature 227, 680-685.

Laurent T. C. and Killander J. (1964) A theory of gel filtration and its experimental verification. J. Chromatogr. 14, 317.

Leski M. L., Moos M., Seamon K., and Agranoff B. W. (1991) Purification and characterization of p68/70 from goldfish brain. Soc. Neurosci. Abstr. 17, 49.

Linial M., Miller K., and Scheller R. H. (1989) VAT-1: an abundant membrane protein from Torpedo cholinergic synaptic vesicles. Neuron 2, 1265-1273.

Maher P. A. and Singer S. J. (1985) Anomalous interaction of the acetylcholine receptor protein with the nonionic detergent Triton X-114. Proc. Natl. Acad. Sci. USA 82, 958-962.

Martin R. G. and Ames B. N. (1961) A method for determining the sedimentation behavior of enzymes: application to protein mixtures. J. Biol. Chem. 236, 1372-1379.

Masters B. S. S., Williams C. H., and Kamin H. (1967) The preparation and properties of microsomal TPNH-cytochrome $c$ reductase from pig liver. Methods Enzymol. 10, 565-573.

Moss D. J. (1983) Cytoskeleton-associated glycoproteins from chicken sympathetic neurons and chicken embryo brain. Eur. J. Biochem. 133, 291-297.

Murray M. (1976) Regeneration of retinal axons into the goldfish optic tectum. J. Comp. Neurol. 168, 175-196.

Perry G. W., Burmeister D. W., and Grafstein B. (1985) Changes in protein content of goldfish optic nerve during degeneration and regeneration following nerve crush. J. Neurochem. 44, $1142-1151$.

Porath J., Carlsson J., Olsson I., and Belfrage G. (1975) Metal chelate affinity chromatography, a new approach to fractionation. Nature 258, 598-599.

Segrest J. P., Jackson R. L., Andrews E. P., and Marchesi V. T. (1971) Human erythrocyte membrane glycoprotcin: a re-evaluation of the molecular weight as determined by SDS-polyacrylamide gel electrophoresis. Biochem. Biophys. Res. Commun. 44, 390-395.

Shephard E. A. H. and Hubscher G. (1969) Phosphatidate biosynthesis in mitochondrial subfractions of rat liver. Biochem. $J$ 113, 429-440. 
Sherman M. R. (1975) Physical-chemical analysis of steroid hormone receptors. Methods Enzymol, 36, 211-234.

Siegel L. M. and Monty K. J. (1966) Determination of molecular weights and frictional ratios in impure systems by use of gel filtration and density gradient centrifugation. Application to crude preparations of sulfite and hydroxylamine reductases. Biochim. Biophys. Acta 112, 346-362.

Sottocasa G. L., Kuylenstierna B., Ernster L., and Bergstrand A. (1967) An electron-transport system associated with the outer membrane of living mitochondria. A biochemical and morphological study. J. Cell Biol. 32, 415-438.

Sperry R. W. (1963) Chemoaffinity in the orderly growth of nerve fiber patterns and connections. Proc. Natl. Acad. Sci. USA $\mathbf{5 0}$, 703-710.

Sun G. Y., Huang H. M., Kelleher J. A., Stubbs E. B. Jr., and Sun A. Y. (1988) Marker enzymes, phospholipids and acyl group composition of a somal plasma membrane fraction isolated from rat cerebral cortex: a comparison with microsomes and synaptic plasma membranes. Neurochem. Int. 12, 69-77.

Swanson M. L., Keast R. K., Jennings M. L., and Pessin J. E. (1988)
Heterogeneity in the human erythrocyte band 3 anion-transporter revealed by Triton X-114 phase partitioning. Biochem. J. 255, 229-234.

Tesser P., Jones P. S., and Schechter N. (1986) Elevated levels of retinal neurofilament mRNA accompany optic nerve regeneration. $J$. Neurochem. 47, 1235-1243.

Volk T. and Geiger B. (1986) A-CAM: a 135-kD receptor of intercellular adherens junctions. 1 . Immunoelectron microscopic localization and biochemical studies. $J$. Cell Biol. 103, 14411450.

Wilmot G. R. (1993) Properties and localization of the goldfish protein p68/70. Doctoral Thesis, University of Michigan. University Microfilms, Ann Arbor, Michigan.

Wilmot G. R., Raymond P. A., and Agranoff B. W. (1993) The expression of the protein p68/70 within the goldfish visual system suggests a role in both regeneration and neurogenesis. $J$. Neurosci. 13, 387-401.

Xu Z., Buelt M. K., Banaszak L. J., and Bernlohr D. A. (1991) Expression, purification, and crystallization of the adipocyte lipid binding protein. J. Biol. Chem. 266, 14367-14370. 